\title{
Association between cluster of differentiation 24 (CD24) polymorphism, talin-1 gene expression and hepatocellular carcinoma prevalence in the Egyptian population
}

Mohamed M. Hafez ${ }^{1}$, Lina Jamil M. Abdel-Hafez², Lubna Jamil ${ }^{3}$, Sherine M. Ibrahim

\author{
${ }^{1}$ Department of Biochemistry, Faculty of Pharmacy, Ahram Canadian University, \\ October 6 City, Giza, Egypt \\ ${ }^{2}$ Department of Microbiology and Immunology, Faculty of Pharmacy, October 6 \\ University, October 6 City, Giza, Egypt \\ ${ }^{3}$ Department of Histology, Faculty of Medicine, October 6 University, October 6 City, \\ Giza, Egypt \\ ${ }^{4}$ Department of Biochemistry, Faculty of Pharmacy, Modern Sciences and Arts \\ University, October 6 City, Giza, Egypt
}

Submitted: 17 October 2020; Accepted: 23 July 2021

Online publication: 13 August 2021

Arch Med Sci

DOI: https://doi.org/10.5114/aoms/140451

Copyright $\odot 2022$ Termedia \& Banach

\begin{abstract}
Introduction: Hepatitis $C$ is considered one of the most common diseases in Egypt. We aim to clarify the association between cluster of differentiation 24 (CD24) polymorphism, talin-1 gene expression, and the prevalence of hepatocellular carcinoma (HCC) in Egyptian hepatitis C virus (HCV) patients. Material and methods: The link between CD24 polymorphism rs8734 and the prevalence of HCC was assessed between 200 control subjects and 400 HCV patients. Patients were classified as follows: 200 patients with HCV and 200 with HCV and HCC by histopathological assessment and PCR-restriction fragment length polymorphism (PCR-RFLP).

Results: The hepatitis $C$ patients with HCC showed a significant increase in alpha-fetoprotein (AFP) and talin-1 gene expression compared to patients with HCV as well as healthy volunteers. Furthermore, the frequency of CD24 $170 \mathrm{CT} / \mathrm{TT}$ genotype was significantly higher in HCV patients without complications (60\%) compared to CC genotype (40\%) (OR $=6$ at $\chi^{2}=14.41$, $p=0.0007)$, and in HCV with HCC patients (90\%) compared to CC genotype $(10 \%)\left(\mathrm{OR}=36\right.$ at $\left.\chi^{2}=14.41, p=0.0007\right)$.
\end{abstract}

Conclusions: These data suggest that CD24 genetic polymorphism rs8734 and talin-1 gene expression may be a significant determinant for the prevalence of HCC in HCV patients.

Key words: hepatocellular carcinoma, SNP, HCV, CD24, talin-1, alphafetoprotein.

\section{Introduction}

Hepatocellular carcinoma (HCC) was recently reported to be the fifth most common type of malignancy, with a high mortality rate globally [1]. In Egypt, HCC is the fourth most common cancer [2]. Hepatocellular carcinoma is a complicated process that occurs due to multiple risks such as hepatitis C virus (HCV), hepatitis B virus (HBV), consumption of alcohol, and diabetes [3-5]. Hepatitis $C$ virus causes acute and chronic hepatitis.

\author{
Corresponding author: \\ Sherine M. Ibrahim, PhD \\ Faculty of Pharmacy \\ Modern Sciences \\ and Arts University \\ October 6 City, \\ 12566, Cairo, Egypt \\ E-mail: sherinemahmoud@ \\ msa.eun.eg
}


If the HCV is not treated, many pathways can lead to hepatocarcinogenesis [6]. The most frequent pathway is that HCV core protein regulates gene expression, which causes oxidative stress and leads to HCC [7].

Furthermore, recent sequencing studies have revealed that genetic variations are associated with well-established risk factors in certain ethnic populations [8, 9]. Genotype 4 is the most predominant genotype present in Egypt, with subtype $4 \mathrm{a}$ considered to be the dominant subtype [10].

Cluster of differentiation 24 (CD24) is a signal transducer or heat-stable antigen (HSA) that can be defined as a human protein encoded by the CD24 gene. CD24 glycoprotein is present at the surfaces of neuroblasts and most B lymphocytes. It is a glycoprotein encoding gene expressed in $B$ cells and on mature granulocytes. Glycosylphosphatidylinositol (GPI) anchors the encoded protein by cell surface links [11].

The CD24 gene, found on chromosome 6 at position 21, is an alignment to genomic locations with similarity with that on chromosomes 1, 15, 20, and Y. Experimental determinations for corresponding translation and transcription of each genomic location are needed. CD24 polymorphism can affect the risk of development of chronic HCV infection. The CD24 P170T allele is associated with $\mathrm{HCV}$ infection at a higher level. Among the chronic HCV Egyptian patients, CD24 P170T allele shows recessive associate [12]. The rapid progression of HCC and liver cirrhosis in the CD24 P170T allele is significantly higher when compared with CD24 $\mathrm{P} 170 \mathrm{C}$ allele in HCV patients. Deletion of dinucleotide at position 1527 on CD24 can reduce the risk of chronic HCV infection [13]. However, only a few studies have focused on the association between CD24 and the progression of HCC.

Talin-1 is a probable indicator for early diagnosis of cancer since its elevated degree of expression in blood samples from people with cancer was adequate to differentiate them from normal human specimens [14]. Talin-1 is important for cell adhesion and motility, which is a very important factor in neoplasm metastasis and inflammation. Also it is responsible for the activation of integrins, which regulates cell apoptosis and growth of tumors [15].

We conducted this study to emphasize the relation between virus $\mathrm{C}$ and HCC and to clarify the association between cluster of differentiation 24 (CD24) polymorphism, talin-1 gene expression, and prevalence of HCC in Egyptian HCV patients.

\section{Material and methods}

\section{Patient selection}

A total of 600 Egyptian adults individuals were involved in this study.
The inclusion criteria included age $\geq 30$ years and positive HCV RNA tests for HCV patients. A total of 200 healthy controls and 400 patients diagnosed with HCV were included in this study; they were selected from Theodor Bilharz Research Institute (TBRI). Patients were classified as follows: 200 patients diagnosed with chronic hepatitis C without liver carcinoma and 200 patients diagnosed with chronic hepatitis $C$ with liver carcinoma. All cases were diagnosed according to histological assessment, and their clinical stage was determined according to the TNM staging system of the American Joint Committee on Cancer (AJCC) [16]. Liver cirrhosis was diagnosed according to abdominal sonography or liver biopsy. The evaluation of the participants for hepatic function was based on patient history, medical consultation, and serum hepatic function tests, and liver biopsies were done before any antiviral therapies were taken. The epidemiological factors included gender, body mass index (BMI), and age.

Exclusion criteria were defined as follows: patients infected with either hepatitis B virus (HBV) or HIV, patients having a background of any inflammatory diseases such as acute or chronic thyroid diseases, infections, and drug abuse were excluded. Regarding alcohol consumption, patients were excluded if they had up to an average of more than 2 drinks per day, and for persistent smoking habit, patients were excluded if they had smoked one cigarette per day in the latest three months.

The study was approved by Ahram Canadian University (ACU) Human Ethics Committee (PBC2020-04). The study was carried out following the recommendations and regulations of the Declaration of Helsinki. Before participation, all medical histories of all subjects were collected and written informed consent was taken from all participants.

\section{Blood sampling and laboratory assays}

Blood samples were divided into two parts under complete aseptic conditions. The first part was added to tubes containing EDTA $(1 \mathrm{mg} / \mathrm{ml})$ to isolate and extract DNA by spin column-based genomic DNA by removing polymerase chain reaction (PCR) inhibitors such as cations and proteins. The second part was taken into tubes, where serum was obtained by centrifugation at $4000 \mathrm{rpm}$ for $15 \mathrm{~min}$ and serum kept frozen at $-70^{\circ} \mathrm{C}$ for determination of aspartate transaminase (AST) [17], alkaline phosphate (ALP), alanine transaminase (ALT), $\gamma$-glutamyl-transferase (GGT), total cholesterol (TC), and high-density lipoprotein (HDL) [18-20]. Using standard laboratory spectrophotometric methods low-density lipoprotein cholesterol (LDL) and serum alfa-fetoprotein (AFP) levels were estimated using enzyme-linked immunoassay kits (commercial kit purchased from DRG, USA) [21]. 


\section{Genotyping of cluster of differentiation 24}

The cluster of differentiation 24 (CD24) gene amplification was performed using PCR-restriction fragment length polymorphism (PCR-RFLP). By measuring the concentration of each sample with a fluorometer device $1 \mu$ l of Qubit reagent was mixed with $199 \mu$ l of Qubit buffer to form Qubit working solution then $199 \mu$ l of that working solution mixed with $1 \mu \mathrm{l}$ of the DNA sample "from the first step" in a PCR tube. After that the concentration was measured using a fluorometer device [22].

\section{Accession number: rs8734}

Quantitative real-time PCR assay of talin-1: talin-1 gene expression was detected in peripheral blood mononuclear cells (PBMCs). These cells were obtained from peripheral blood by the Ficoll density sedimentation process. A QIAamp viral RNA extraction kit was used for the extraction of total RNA. The quantification process was analyzed using TaqMan Gene Expression assay (Applied Biosystems Inc., Foster City, CA, USA). Levels of talin-1 expression were calculated using the threshold cycle method [23]. The following primers were used in the GRT-PCR [24]:

Talin-1 sense: 5'-TCTCCCAAA ATGCCAAGAAC-3' Anti-sense: 5'-TGGCTATTGG GGTCAGAGAC-3' Glyceraldehyde-3-phosphate dehydrogenase (GAPDH) sense: 5'-CCACTCC TCCACCTTTGAC-3' Anti-sense: 5'-ACCCTGT TGCTGTAGCCA-3'.

\section{Hepatic histopathological assessment by hematoxylin and eosin and Masson's trichrome staining}

Liver specimens were taken by needle biopsy from all patients with hepatitis C upon signing a written consent form. Liver tissues were all treated with $10 \%$ neutral buffered formalin for $24 \mathrm{~h}$ and histo-processed. The blocks were then sliced into $3 \mu \mathrm{m}$ thicknesses, using a rotary microtome. Parts were stained utilizing hematoxylin and eosin ( $H$ \& E) stain [25].

Three colors can be used for muscle staining, collagen fibers, fibrin, and erythrocytes. The fundamental principle in trichrome staining is that less porous tissue is colored by the small dye molecule, whereas a higher molecular dye can infiltrate [26]. Hematoxylin and eosin and Masson's trichrome staining have been used for histopathological analysis. The level of steatosis, lobular inflammatory processes, and non-alcoholic steatohepatitis (NASH) was calculated using the SAF scoring system. The steatosis, activity and fibrosis score system (SAF) is a non-alcoholic fatty liver disease (NAFLD) score based on histological severity. All biopsies were classified according to the SAF system, and the severity of the disease was classified as mild, moderate or severe. The SAF activity score was measured by hepatocellular ballooning and lobular inflammation. Histopathological severe disease was described as SAF activity score > 3 for bridging fibrosis or cirrhosis. The regression formula for the fibrosis severity estimation includes 6 variables: age, years, BMI $\left(\mathrm{kg} / \mathrm{m}^{2}\right)$, fasting glucose (FG)/diabetes, platelet count and albumin (g/dl) and AST/ALT ratio [27].

\section{Statistical analysis}

The differences in demographic characteristics between healthy controls and HCC patients were compared using Fisher's exact test and the Mann-Whitney $U$ test. These data were expressed as mean $\pm S E M$ and compared between groups by Student's $t$-test. The data were analyzed using SPSS 25 software (IBM SPSS, USA). $P$ values $<0.05$ were regarded as statistically significant.

\section{Results}

\section{Characteristics of subjects}

Since various risk factors have been related to the pathogenesis and prevalence of liver cancer such as alcohol consumption, gender, and age, we first compared the mean and SEM for the clinical data of $400 \mathrm{HCV}$ patients with those from 200 normal controls (Table I). There was no significant difference between the study groups in the sex distribution, BMI, or age. For the liver function tests, the level of ALT is significantly higher in hepatitis $C$ patients (mean \pm SEM $=125 \pm 20.53$ IU/l) and hepatitis $C$ with HCC patients (mean \pm SEM = $135 \pm 11.69 \mathrm{IU} / \mathrm{l})$ than in healthy control subjects (mean $\pm \mathrm{SEM}=27.8 \pm 0.61 \mathrm{IU} / \mathrm{l}$ ). Meanwhile, there is no significance in it between the HCV group and the HCV with HCC group at $p<0.05$. As regards GGT and ALP levels, both were significantly higher in all HCV patients than controls. Also, there is a significant difference in it between the HCV with HCC group and the HCV group at $p<0.05$. Additionally, the serum AFP level in hepatitis C with HCC patients showed the highest significant increase to $4570 \pm 294 \mathrm{ng} / \mathrm{ml}$ compared to the healthy control group, $6.6 \pm 0.8 \mathrm{ng} / \mathrm{ml}(p \leq 0.05)$. Additionally, we observed that tobacco smoking and alcohol consumption are strongly associated with the prevalence of HCC (Table I). The power of the study was calculated as follows: total sample size: 600, number of groups: 3 , effect size: 0.15 , critical F: 3, and power: 0.9 .

\section{Histopathological examination}

Figure 1 shows a photomicrograph in of control human liver section showing normal hepatic lob- 
Mohamed M. Hafez, Lina Jamil M. Abdel-Hafez, Lubna Jamil, Sherine M. Ibrahim

Table I. Clinical and hemodynamic characteristics of participants

\begin{tabular}{|c|c|c|c|c|}
\hline Variables & Control & $\mathrm{HCV}$ & HCV with HCC & $P$-value \\
\hline Sex & $200(35 \mathrm{M} / 35 \mathrm{~F})$ & $200(30 \mathrm{M} / 40 \mathrm{~F})$ & $200(35 \mathrm{M} / 35 \mathrm{~F})$ & 0.01 \\
\hline Age [years] & $40.51 \pm 0.66$ & $41.38 \pm 0.55$ & $40.38 \pm 0.55$ & 0.05 \\
\hline $\mathrm{BMI}\left[\mathrm{kg} / \mathrm{m}^{2}\right]$ & $23 \pm 0.22$ & $24 \pm 0.26$ & $24 \pm 0.12$ & 0.01 \\
\hline Waist & 0.75 & 0.82 & 0.83 & 0.01 \\
\hline Waist/hip ratio & 0.83 & 0.85 & 0.84 & 0.01 \\
\hline Cigarette smoking: & & & & 0.01 \\
\hline No & 170 & 55 & 45 & \\
\hline Yes & 30 & 145 & 155 & \\
\hline Alcohol consumption: & & & & 0.001 \\
\hline No & 55 & 26 & 20 & \\
\hline Yes & 15 & 44 & 50 & \\
\hline Tumor status: & & & & 0.001 \\
\hline$T 1+T 2$ & & & $128(64 \%)$ & \\
\hline $\mathrm{T} 3+\mathrm{T} 4$ & & & $72(36 \%)$ & \\
\hline $\mathrm{SBP}[\mathrm{mm} \mathrm{Hg}]$ & $120.3 \pm 8.44$ & $140 \pm 7.32^{\mathrm{a}, \mathrm{b}}$ & $145 \pm 7.32^{\mathrm{a}, \mathrm{b}}$ & 0.01 \\
\hline $\mathrm{DBP}[\mathrm{mm} \mathrm{Hg}]$ & $70.5 \pm 5.41$ & $85 \pm 4.32^{a, b}$ & $95 \pm 4.32^{\mathrm{a}, \mathrm{b}}$ & 0.01 \\
\hline Serum TAG [mg/dl] & $111.6 \pm 2.2$ & $171.9 \pm 4.05^{a}$ & $175.9 \pm 4.05^{\mathrm{a}}$ & 0.001 \\
\hline Serum TC $[\mathrm{mg} / \mathrm{dl}]$ & $150.3 \pm 1.70$ & $230.7 \pm 3.09^{a}$ & $228.7 \pm 3.09^{\mathrm{a}}$ & 0.001 \\
\hline Serum HDL-C [mg/dl] & $56.53 \pm 0.57$ & $29.71 \pm 0.92^{a}$ & $30.71 \pm 0.92^{\mathrm{a}}$ & 0.01 \\
\hline Serum LDL-C [mg/dl] & $95.37 \pm 1.81$ & $150.6 \pm 3.4^{\mathrm{a}}$ & $155.6 \pm 3.4^{a}$ & 0.01 \\
\hline GGT [IU/I] & $21.5 \pm 0.77$ & $85.3 \pm 0.66^{a}$ & $96.1 \pm 0.69^{a, b}$ & 0.01 \\
\hline ALP [IU/I] & $60 \pm 2.78$ & $192 \pm 1.56^{\mathrm{a}}$ & $176.3 \pm 0.85^{a, b}$ & 0.001 \\
\hline AST [IU/I] & $20.9 \pm 0.45$ & $120.5 \pm 14.57^{a}$ & $131 \pm 10.77^{a, b}$ & 0.001 \\
\hline $\mathrm{ALT}[\mathrm{IU} / \mathrm{l}]$ & $27.8 \pm 0.61$ & $125 \pm 20.53^{a}$ & $135 \pm 11.69^{a}$ & 0.001 \\
\hline Serum AFP [ng/ml] & $6.6 \pm 0.8$ & $2800.9 \pm 110^{a}$ & $4570 \pm 294^{a, b}$ & 0.01 \\
\hline
\end{tabular}

$H C V$ - hepatitis C virus, BMI - body mass index, TAG - triacylglycerol, TC - total cholesterol, HDL-C - high-density lipoprotein cholesterol, $L D L-C$ - low-density lipoprotein cholesterol, ALP - alkaline phosphatase test, AST - aspartate aminotransferase, ALT - alanine aminotransferase, GGT - $\gamma$-glutamyl-transferase, AFP - alpha-fetoprotein, SBP - systolic blood pressure, DBP-diastolic blood pressure. Data are given as mean + SEM. ${ }^{a}$ Significantly different from control group at $p<0.05$, bsignificantly different from HCV group at $p<0.05$.

ules' architecture. In Figure 2 the histopathological sections reveal human liver sections showing (A and B): Mallory-Denk bodies and microvesicular steatosis (C): a human liver section with NASH was demonstrated showing peri-sinusoidal fibro-

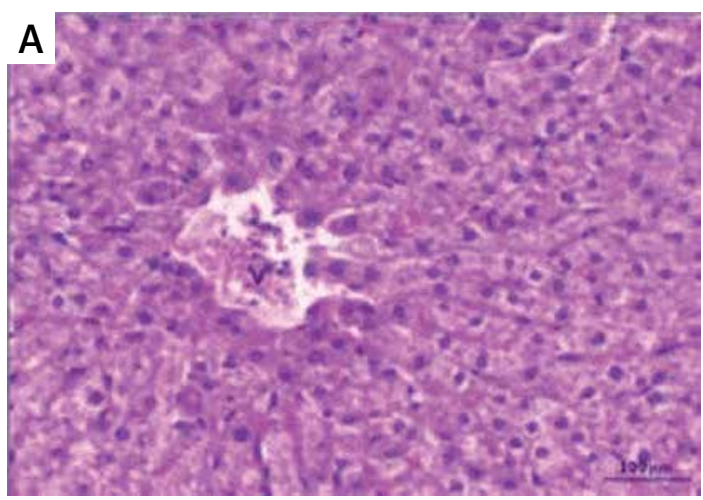

sis (Masson's trichrome) with no CD4 expression. In contrast, histology analysis in Figure 3 indicates that the tumors in the group of hepatitis $\mathrm{C} \mathrm{pa-}$ tients with complications are malignant HCC, with the expression of CD4 on the inflammatory cells

Figure 1. A photomicrograph in control human liver section showing normal architecture of hepatic lobules, in the form of hepatocytes as plates radiating from the central vein. The liver plates were separated from each other by irregular sinusoids. The hepatocytes appeared polyhedral in shape with acidophilic cytoplasm with large, rounded and vesicular nuclei (H \& E, 100x)

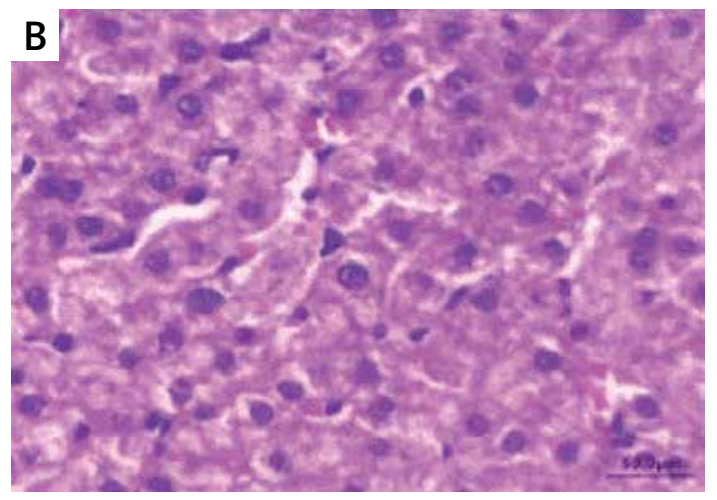



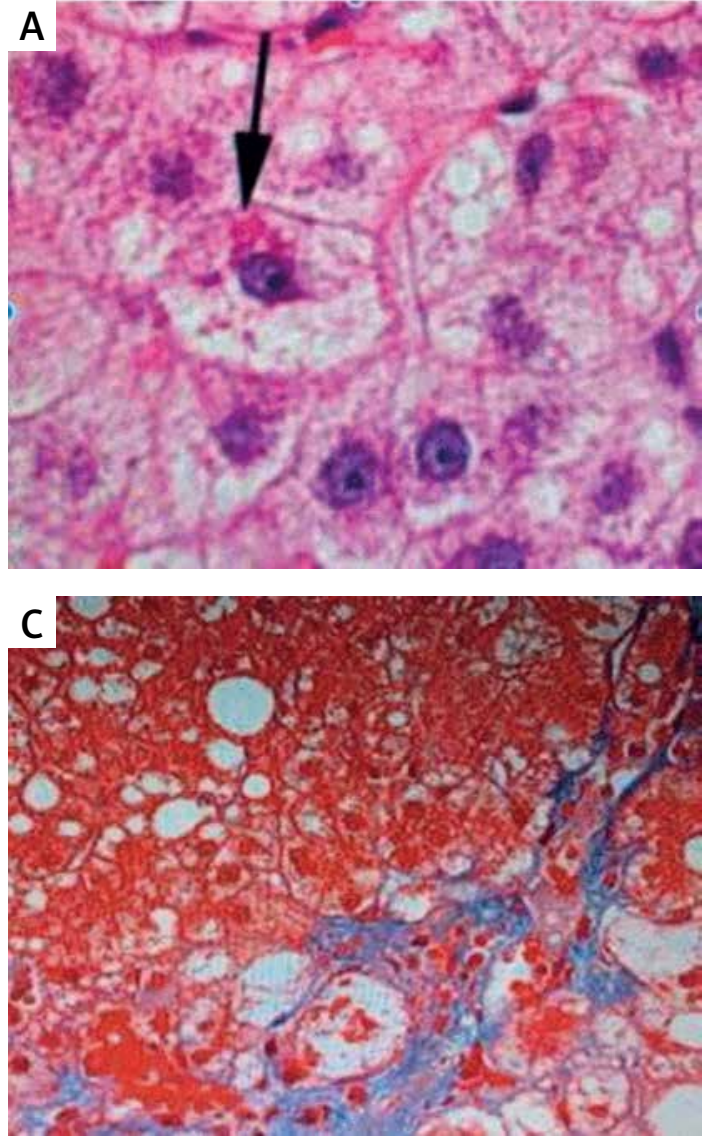

which are determined by its heterogeneous and large nuclei; cancer cells are also characterized by double nuclei, showing: (A) masses of malignant cells with frequent mitosis, hyperchromatic nuclei and trabecular growth pattern (H \& E 100x); (B) pseudoglandular growth pattern (H \& E 100x); (C) loss of architecture, cellular degeneration and solid growth pattern (H \& E 200x); (D) loss of architecture with dilated central vein and giant cell formation. These data focused on the correlation between $C D 24$ gene variation and the rapid development of HCC.

\section{Genotype distribution and allele} frequencies of CD24 $170 \mathrm{C} / \mathrm{T}$ polymorphism in hepatitis $C$ patient groups versus control group

The frequencies of CD24 170 CT/TT genotype were significantly higher in hepatitis $C$ patients without complications (60\%) compared to CC genotype (40\%) with OR $=6$ at $\chi^{2}=14.41, p=0.0007$. Also the frequencies of CD24 $170 \mathrm{CT} / \mathrm{TT}$ genotype were significantly higher in hepatitis $C$ patients with HCC (90\%) compared to CC genotype (10\%) with $\mathrm{OR}=36$ at $\chi^{2}=14.41, p=0.0007$ (Table II). No significant differences were found between the levels of AFP, AST, ALT, or GGT and the CD24

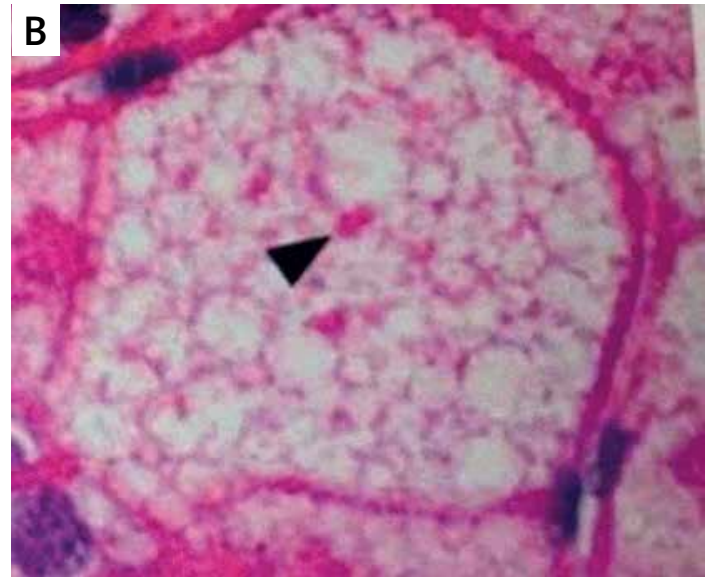

Figure 2. A - a photomicrograph in human liver section with hepatitis $C$ infection showing Mallory-Denk bodies (arrow) and fatty infiltration ( $\mathrm{H} \& \mathrm{E}$, 40x). B - a photomicrograph in human liver section with hepatitis $C$ infection showing Megamitochondria (arrow head) in cell with microvesicular steatosis ( $\mathrm{H} \& \mathrm{E} 40 \mathrm{x}$ ). C - a photomicrograph of human liver section with NASH showing Peri-sinusoidal fibrosis (Masson's trichrome, 20x)

$170 \mathrm{C} / \mathrm{T}$ polymorphisms in HCC patients (Table III). CD24 polymorphism correlated with prognosis in HCC patients which is estimated by its correlation with tumor status T1+T2 at $p<0.0001$ in Figure 4. Additionally, Kaplan-Meier curve analysis was conducted to estimate the overall survival rate for the different genotypes of CD24 polymorphism of the recipients at $p<0.0001$ as presented in Figure 5 .

\section{Talin-1 gene expression}

Table IV shows a 1.6-fold significant increase in talin-1 expression in HCV patients (mean \pm SEM $=8.07 \pm 0.12$ and $14.27 \pm 0.12$ respectively) compared to the control group (mean \pm SEM $=6.15$ $\pm 0.1)$ at $p<0.0001$. Moreover, there was a 1.3-fold significant increase of talin-1 expression in HCV with HCC patients (mean \pm SEM $=10.27 \pm 0.12$ ) compared to $\mathrm{HCV}$ patients (mean $\pm \mathrm{SEM}=8.07$ \pm 0.12 ) at $p<0.0001$ as shown in Figure 6. A significant correlation between CD24 polymorphism genotypes and talin-1 gene expression is clearly represented among our groups at $p<0.0001$ in Figure 7. To evaluate the diagnostic value of talin-1 gene expression, we used ROC methods to calculate the sensitivity and specificity as shown in Figure 8. The AUC of talin-1 gene expression between the patients with HCV and HCC with those 

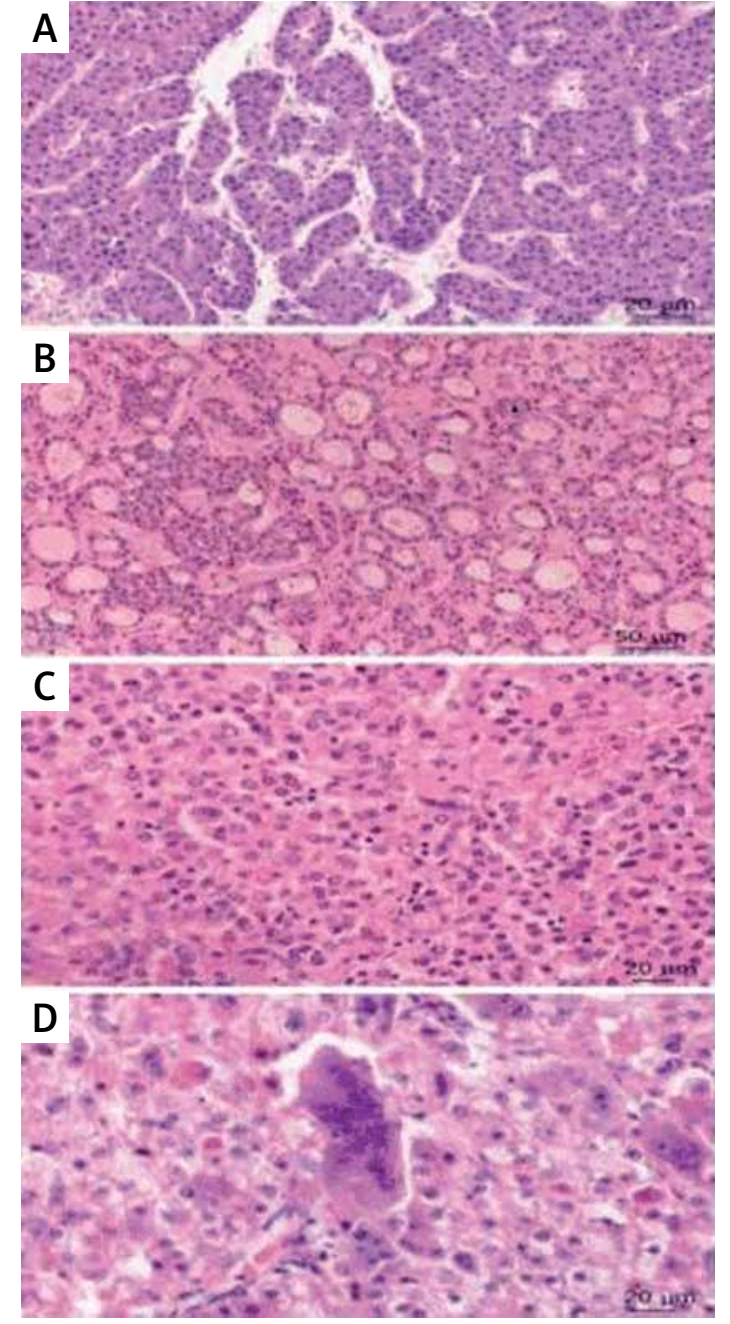

Figure 3. A photomicrograph in human liver section with hepatitis $C$ infection and hepatocellular carcinoma showing: A - masses of malignant cells with frequent mitosis, hyper chromatic nuclei and trabecular growth pattern (H \& E, 100x); B - pseudo glandular growth pattern (H \& E, 100x); C - loss of architecture, cellular degeneration and Solid growth pattern (H \& E, 200x). D - loss of architecture with dilated central vein and giant cell formation ( $H$ \& E, 200x)

with HCV was 0.9 (95\% Cl: 0.52-0.69; $p=0.009)$ for predicting the risk of developing cancer, indicating that talin-1 gene expression had significant accuracy as a predictor for cancer prevalence risk.

\section{SAF scores for biopsies of HCV patients}

Tables $\mathrm{V}$ and $\mathrm{VI}$ show the most frequent diagnosis of hepatitis $C$ patients. The baseline diagnosis with NASH was concordant with the reference classification which states that less than -1.455 indicates the absence of fibrosis (FO-F2), between -1.455 and 0.675 is an indeterminate score while more than 0.675 indicates the presence of fibrosis (F3-F4). Table $V$ shows the most frequent diagnosis among the two pathologists in HCV pa- tients with HCC. 40 out of 70 (57\%) diagnosed with NASH were concordant with the reference classification. In Table VI, 34 out of 70 (49\%) HCV patients without HCC were diagnosed with NASH with full agreement between reference and baseline classification.

Table VII shows the distribution frequency of CD24 gene variation among the 400 patients with HCV with their clinical status and histological examinations. The patients with HCV were evaluated to understand the effect of CD24 170 CT/ TT genotypes on the clinical stage, lymph node involvement, distant metastasis, vascular invasion, and liver cirrhosis. There was a significant difference in the effect of CD24 170 CT/TT genotype on lymph node involvement, distant metastasis and liver cirrhosis as well.

\section{Discussion}

In our study, we investigated the association between CD24 polymorphisms and the prevalence of HCC in HCV patients. Hepatocellular carcinoma is the third most common cause of death due to cancer worldwide [28]. In Egypt, HCC represents around $1.68 \%$ of the total malignancies and $11.75 \%$ of all digestive organs' malignancies and metabolic syndrome diseases [29]. The distribution analysis of the CD24 genotypes involved 400 HCV patients and 200 normal controls indicating that the frequencies of CD24 170 CT/TT genotype were significantly higher in HCV patients without complications (60\%) compared to CC genotype $(40 \%)$ with $\mathrm{OR}=6$ at $\chi^{2}=14.41, p=0.0007$, and the frequencies of CD24 170 CT/TT genotype were significantly higher in HCV with HCC (90\%) compared to CC genotype (10\%) with OR $=36$ at $\chi^{2}=$ $14.41, p=0.0007$.

Moreover, among the chronic HCV Egyptian patients, the CD24 P170T allele shows a stronger association with the rapid development of HCC and liver cirrhosis compared with the CD24 P170 C allele. In contrast, deletion of the dinucleotide at position 1527 on CD24 can reduce the development of chronic HCV infection [30]. In addition, CD24 polymorphisms may increase the genetic susceptibility factor for HBV infection. This was investigated by a recent study which included 609 HBV patients and 383 healthy controls; the study showed an increased risk of prevalence of HBV infection in patients with the P170T/T genotype compared with $\mathrm{P} 170 \mathrm{C} / \mathrm{T}$ and $\mathrm{P} 170 \mathrm{C} / \mathrm{C}$ genotypes using the logistic regression model [31].

An important explanation for how the CD24 SNP affects the risk of development of chronic $\mathrm{HCV}$ infection. Our previous results have suggested that the P170T allele, which is expressed at a higher level than P170C, encodes a certain protein, which is responsible for the progression 
Table II. Difference in genotype frequency of CD24 SNP 170 between all studied groups

\begin{tabular}{|lccccc|}
\hline Groups & $N$ & \multicolumn{2}{c|}{ Genotype frequency } & OR & 95\% CI \\
\cline { 3 - 5 } & & CC & CT + TT & & \\
\hline Control & 200 & $160(80 \%)$ & $40(20 \%)$ & 6 & $0.88-13.83$ \\
\hline HCV & 200 & $80(40 \%)$ & $120(60 \%)$ & 36 & $2.07-30.89$ \\
\hline HCV with HCC & 200 & $20(10 \%)$ & $180(90 \%)$ & $\chi^{2}=14.41, p=0.0007^{*}$ & \\
\hline
\end{tabular}

Statistically significant difference at $p<0.05$ using $\chi^{2}$ test.

HCC - hepatocellular carcinoma, HCV - hepatitis C virus.

Table III. Association of CD24 C/T SNP 170 genotypic frequencies with HCC laboratory status

\begin{tabular}{|lcccc|}
\hline Characteristic & $\alpha$-Fetoprotein $[\mathrm{ng} / \mathrm{ml}]$ & AST $[\mathrm{IU} / \mathrm{l}]$ & ALT $[\mathrm{IU} / \mathrm{I}]$ & $\mathrm{GGT}$ \\
\hline CD24 C/T SNP 170 & & & & \\
\hline CC & $2800.2 \pm 110$ & $125.1 \pm 20.6$ & $120.2 \pm 14$ & $85 \pm 0.66$ \\
\hline CT + TT & $4570 \pm 294$ & $135.2 \pm 11.6$ & $131.3 \pm 10$ & $96 \pm 0.69$ \\
\hline$P$-value & 0.448 & 0.537 & 0.501 & 0.545 \\
\hline
\end{tabular}

Mann-Whitney $U$ test was used between two groups. ${ }^{*} P$-value $<0.05$ indicates statistical significance.

HCC - hepatocellular carcinoma, AST - aspartate aminotransferase, ALT-alanine aminotransferase, GGT- $\gamma$-glutamyl-transferase.

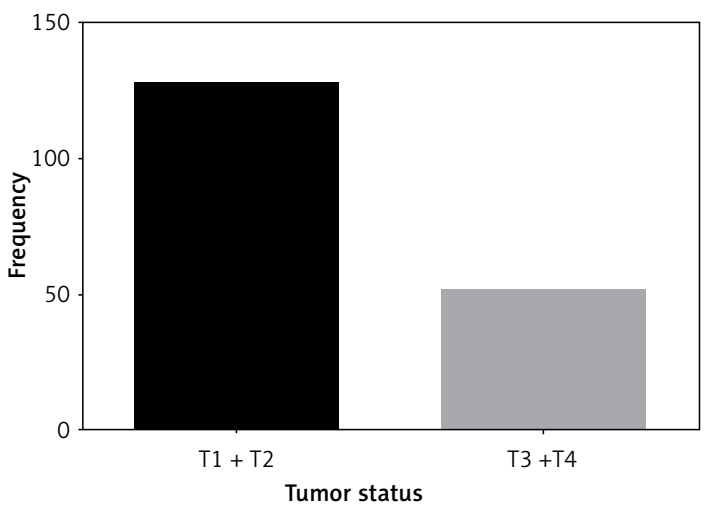

Figure 4. Correlation between frequency of CD24 polymorphism and tumor status in hepatocellular carcinoma patients, $p<0.0001$

Table IV. Gene expression of talin-1 in hepatitis C virus patients (HCV patients) and hepatitis $C$ virus with hepatocellular carcinoma patients ( $\mathrm{HCV}$ with HCC patients) compared to control group at $p<0.05$

\begin{tabular}{|c|c|}
\hline Group & Talin-1 gene expression \\
\hline Control & $6.15 \pm 0.1$ \\
\hline $\mathrm{HCV}$ & $8.07 \pm 0.12^{a}$ \\
\hline $\mathrm{HCV}$ with $\mathrm{HCC}$ & $10.27 \pm 0.12^{a, b}$ \\
\hline
\end{tabular}

of chronic HCV infection by affecting the efficiency of cleavage of posttranslational GPI. These results agree with another study [32] which supports the idea that the P170T allele affects the progression of chronic HCV infection through posttranslational mechanisms. Given the fact that CD24 is expressed mainly in the neuronal and hematopoietic cells, Huang and Hsu31 stated that there are many other tumor cells that

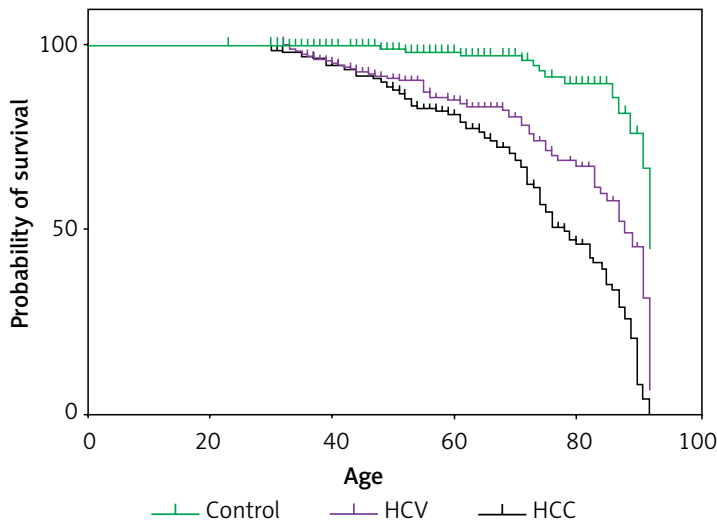

Figure 5. Kaplan-Meier curves for probability of survival by CD24 polymorphism among groups at $p<0.0001$

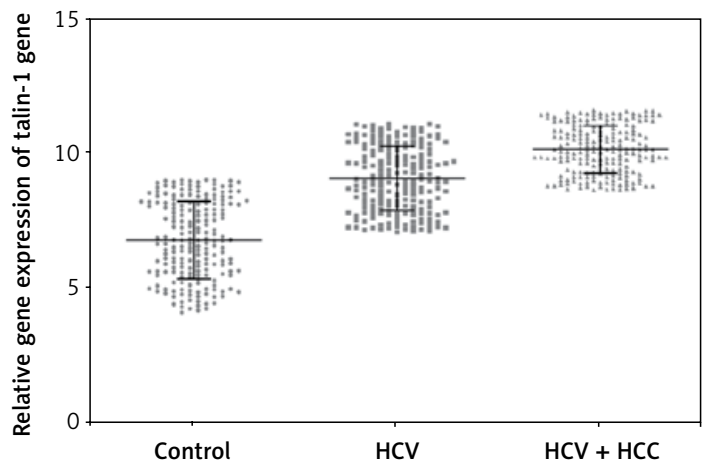

Figure 6. Column scatter dot plot showing talin-1 gene expression among control, $\mathrm{HCV}$, and $\mathrm{HCV}+$ HCC groups, $p<0.0001$

have been shown to increase the expression of CD24 mainly in liver tumors [21]. Another study [33] also suggested that CD24 SNPs are a prognostic marker for hepatic carcinoma. In this regard, another study confirmed that during liver 


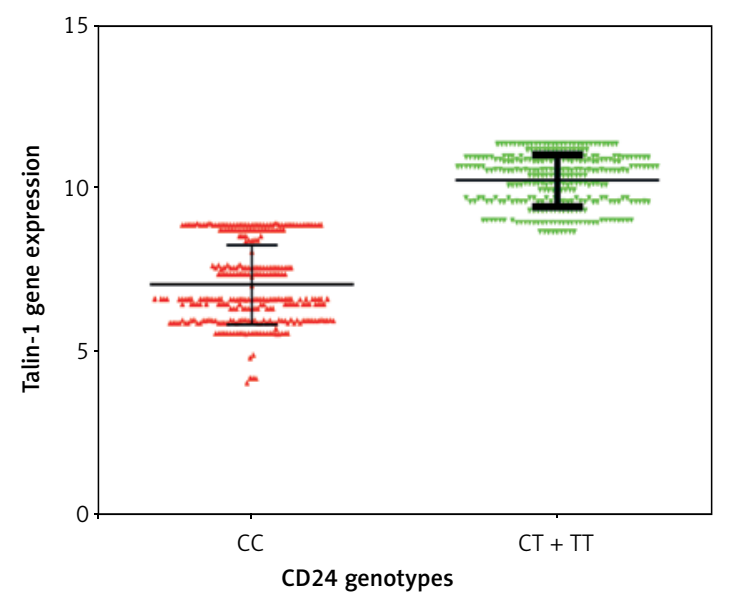

Figure 7. Correlation of CD24 170 SNP genotypes with talin-1 gene expression in hepatitis C virus patients, $p<0.0001$

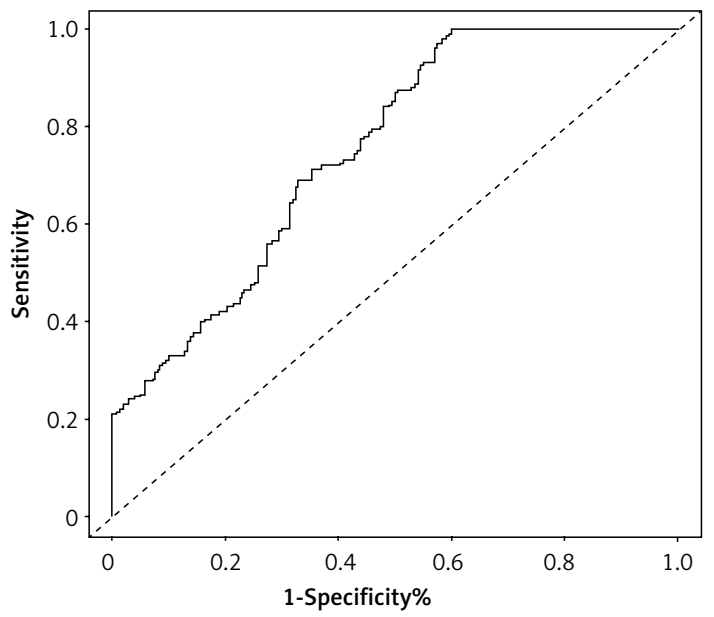

Figure 8. AUC curve analysis of talin-1 gene expression, $p<0.0001$, AUC $=0.9$

Table V. Evaluation of liver biopsies by the liver pathologists in hepatitis C virus patients with hepatocellular carcinoma

\begin{tabular}{|c|c|c|c|c|}
\hline Case & Reference classification & Algorithmic classification & SAF & Disease severity \\
\hline 1 & $\mathrm{NASH}$ & NASH & $\mathrm{S} 2 \mathrm{~A} 4 \mathrm{~F} 1$ & significant \\
\hline 2 & steatosis & steatosis & S1A1F1 & mild \\
\hline 3 & $\mathrm{NASH}$ & $\mathrm{NASH}$ & S1A4F3 & significant \\
\hline 4 & $\mathrm{NASH}$ & $\mathrm{NASH}$ & S3A1F2 & significant \\
\hline 5 & steatosis & steatosis & S3A1F0 & mild \\
\hline 6 & NASH & NASH & S3A3F2 & significant \\
\hline 7 & NASH & NASH & S2A4F1 & significant \\
\hline 8 & steatosis & steatosis & S1A1F1 & mild \\
\hline 9 & NASH & $\mathrm{NASH}$ & S3A1F2 & significant \\
\hline 10 & $\mathrm{NASH}$ & NASH & S2A4F1 & significant \\
\hline 11 & NASH & NASH & S3A1F2 & significant \\
\hline 12 & NASH & NASH & S2A4F1 & significant \\
\hline 13 & steatosis & steatosis & S1A1F1 & mild \\
\hline 14 & $\mathrm{NASH}$ & NASH & S3A3F2 & significant \\
\hline 15 & NASH & NASH & S2A4F1 & significant \\
\hline 16 & steatosis & steatosis & S1A1F1 & mild \\
\hline 17 & steatosis & steatosis & S1A1F1 & mild \\
\hline 18 & NASH & NASH & S3A4F3 & significant \\
\hline 19 & $\mathrm{NASH}$ & $\mathrm{NASH}$ & S3A3F2 & significant \\
\hline 20 & $\mathrm{NASH}$ & $\mathrm{NASH}$ & S2A4F1 & significant \\
\hline 21 & $\mathrm{NASH}$ & $\mathrm{NASH}$ & $\mathrm{S} 2 \mathrm{~A} 4 \mathrm{~F} 1$ & significant \\
\hline 22 & steatosis & steatosis & S1A1F1 & mild \\
\hline 23 & steatosis & steatosis & S1A0F0 & mild \\
\hline 24 & steatosis & steatosis & S1A1F1 & mild \\
\hline 25 & $\mathrm{NASH}$ & $\mathrm{NASH}$ & S3A3F2 & significant \\
\hline 26 & $\mathrm{NASH}$ & NASH & S3A1F2 & significant \\
\hline 27 & NASH & NASH & S3A1F2 & significant \\
\hline 28 & NASH & NASH & S2A4F1 & significant \\
\hline 29 & steatosis & steatosis & S1A0F0 & mild \\
\hline 30 & steatosis & steatosis & S1A1F1 & mild \\
\hline
\end{tabular}


Table V. Cont.

\begin{tabular}{|c|c|c|c|c|}
\hline Case & Reference classification & Algorithmic classification & SAF & Disease severity \\
\hline 31 & steatosis & steatosis & S1A0F0 & mild \\
\hline 32 & $\mathrm{NASH}$ & $\mathrm{NASH}$ & S3A3F2 & significant \\
\hline 33 & $\mathrm{NASH}$ & $\mathrm{NASH}$ & S3A1F2 & significant \\
\hline 34 & $\mathrm{NASH}$ & $\mathrm{NASH}$ & S3A1F2 & significant \\
\hline 35 & $\mathrm{NASH}$ & $\mathrm{NASH}$ & S2A4F1 & significant \\
\hline 36 & $\mathrm{NASH}$ & $\mathrm{NASH}$ & S3A1F2 & significant \\
\hline 37 & steatosis & steatosis & $\mathrm{S} 1 \mathrm{~A} 1 \mathrm{~F} 1$ & mild \\
\hline 38 & $\mathrm{NASH}$ & $\mathrm{NASH}$ & S3A1F2 & significant \\
\hline 39 & $\mathrm{NASH}$ & $\mathrm{NASH}$ & S3A1F2 & significant \\
\hline 40 & $\mathrm{NASH}$ & $\mathrm{NASH}$ & $\mathrm{S} 2 \mathrm{~A} 4 \mathrm{~F} 1$ & significant \\
\hline 41 & steatosis & steatosis & S3A1F0 & mild \\
\hline 42 & steatosis & steatosis & S1A1F1 & mild \\
\hline 43 & steatosis & steatosis & S1A0F0 & mild \\
\hline 44 & $\mathrm{NASH}$ & $\mathrm{NASH}$ & S3A1F2 & significant \\
\hline 45 & steatosis & steatosis & S3A1F0 & mild \\
\hline 46 & steatosis & steatosis & S1A1F1 & mild \\
\hline 47 & $\mathrm{NASH}$ & $\mathrm{NASH}$ & S3A3F2 & significant \\
\hline 48 & $\mathrm{NASH}$ & $\mathrm{NASH}$ & S3A3F2 & significant \\
\hline 49 & $\mathrm{NASH}$ & $\mathrm{NASH}$ & $\mathrm{S} 2 \mathrm{~A} 4 \mathrm{~F} 1$ & significant \\
\hline 50 & steatosis & steatosis & S3A1F0 & mild \\
\hline 51 & $\mathrm{NASH}$ & $\mathrm{NASH}$ & S3A3F2 & significant \\
\hline 52 & steatosis & steatosis & S1A0F0 & mild \\
\hline 53 & steatosis & steatosis & S1A1F1 & mild \\
\hline 54 & $\mathrm{NASH}$ & $\mathrm{NASH}$ & S3A3F2 & \\
\hline 55 & NASH & NASH & S2A4F1 & significant \\
\hline 56 & $\mathrm{NASH}$ & $\mathrm{NASH}$ & S3A3F2 & significant \\
\hline 57 & steatosis & steatosis & S2A1F1 & mild \\
\hline 58 & steatosis & steatosis & S1A1F1 & mild \\
\hline 59 & NASH & $\mathrm{NASH}$ & S3A1F2 & significant \\
\hline 60 & steatosis & steatosis & S2A1F1 & mild \\
\hline 61 & steatosis & steatosis & S2A1F1 & mild \\
\hline 62 & NASH & $\mathrm{NASH}$ & S2A4F1 & significant \\
\hline 63 & NASH & $\mathrm{NASH}$ & S3A3F2 & significant \\
\hline 64 & $\mathrm{NASH}$ & $\mathrm{NASH}$ & S3A1F2 & significant \\
\hline 65 & $\mathrm{NASH}$ & $\mathrm{NASH}$ & $\mathrm{S} 2 \mathrm{~A} 4 \mathrm{~F} 1$ & significant \\
\hline 66 & steatosis & steatosis & S1A1F1 & mild \\
\hline 67 & steatosis & steatosis & S2A1F1 & mild \\
\hline 68 & steatosis & steatosis & S1A1F1 & mild \\
\hline 69 & NASH & $\mathrm{NASH}$ & S3A1F2 & significant \\
\hline 70 & $\mathrm{NASH}$ & $\mathrm{NASH}$ & $\mathrm{S} 2 \mathrm{~A} 4 \mathrm{~F} 1$ & significant \\
\hline 71 & $\mathrm{NASH}$ & $\mathrm{NASH}$ & S3A1F2 & significant \\
\hline 72 & $\mathrm{NASH}$ & $\mathrm{NASH}$ & $\mathrm{S} 2 \mathrm{~A} 4 \mathrm{~F} 1$ & significant \\
\hline 73 & steatosis & steatosis & S1A0F0 & mild \\
\hline 74 & steatosis & steatosis & $\mathrm{S} 1 \mathrm{~A} 1 \mathrm{~F} 1$ & mild \\
\hline 75 & steatosis & steatosis & $\mathrm{S} 1 \mathrm{~A} 1 \mathrm{~F} 1$ & mild \\
\hline 76 & steatosis & steatosis & $\mathrm{S} 1 \mathrm{~A} 1 \mathrm{~F} 1$ & mild \\
\hline 77 & NASH & $\mathrm{NASH}$ & S3A1F2 & significant \\
\hline
\end{tabular}


Table V. Cont.

\begin{tabular}{|c|c|c|c|c|}
\hline Case & Reference classification & Algorithmic classification & SAF & Disease severity \\
\hline 78 & steatosis & steatosis & S1A1F1 & mild \\
\hline 79 & steatosis & steatosis & S1A1F1 & mild \\
\hline 80 & steatosis & steatosis & S1A1F1 & mild \\
\hline 81 & steatosis & steatosis & S1A0F0 & mild \\
\hline 82 & $\mathrm{NASH}$ & $\mathrm{NASH}$ & S3A1F2 & significant \\
\hline 83 & steatosis & steatosis & S3A1F0 & mild \\
\hline 84 & steatosis & steatosis & S1A1F1 & mild \\
\hline 85 & $\mathrm{NASH}$ & $\mathrm{NASH}$ & S3A3F2 & significant \\
\hline 86 & $\mathrm{NASH}$ & $\mathrm{NASH}$ & S3A3F2 & significant \\
\hline 87 & $\mathrm{NASH}$ & $\mathrm{NASH}$ & S2A4F1 & significant \\
\hline 88 & steatosis & steatosis & S3A1F0 & mild \\
\hline 89 & $\mathrm{NASH}$ & $\mathrm{NASH}$ & S3A3F2 & significant \\
\hline 90 & steatosis & steatosis & S1A0F0 & mild \\
\hline 91 & steatosis & steatosis & S1A1F1 & mild \\
\hline 92 & $\mathrm{NASH}$ & $\mathrm{NASH}$ & S3A3F2 & \\
\hline 93 & $\mathrm{NASH}$ & $\mathrm{NASH}$ & S2A4F1 & significant \\
\hline 94 & $\mathrm{NASH}$ & $\mathrm{NASH}$ & S3A3F2 & significant \\
\hline 95 & steatosis & steatosis & S2A1F1 & mild \\
\hline 96 & steatosis & steatosis & S1A1F1 & mild \\
\hline 97 & $\mathrm{NASH}$ & $\mathrm{NASH}$ & S3A1F2 & significant \\
\hline 98 & steatosis & steatosis & S2A1F1 & mild \\
\hline 99 & steatosis & steatosis & S2A1F1 & mild \\
\hline 100 & $\mathrm{NASH}$ & $\mathrm{NASH}$ & S2A4F1 & significant \\
\hline 101 & $\mathrm{NASH}$ & $\mathrm{NASH}$ & S3A3F2 & significant \\
\hline 102 & $\mathrm{NASH}$ & $\mathrm{NASH}$ & S3A1F2 & significant \\
\hline 103 & $\mathrm{NASH}$ & $\mathrm{NASH}$ & S2A4F1 & significant \\
\hline 104 & $\mathrm{NASH}$ & $\mathrm{NASH}$ & S3A1F2 & significant \\
\hline 105 & steatosis & steatosis & S1A1F1 & mild \\
\hline 106 & steatosis & steatosis & $\mathrm{S} 1 \mathrm{~A} 1 \mathrm{~F} 1$ & mild \\
\hline 107 & $\mathrm{NASH}$ & $\mathrm{NASH}$ & S3A4F3 & significant \\
\hline 108 & $\mathrm{NASH}$ & $\mathrm{NASH}$ & S3A3F2 & significant \\
\hline 109 & $\mathrm{NASH}$ & $\mathrm{NASH}$ & S2A4F1 & significant \\
\hline 110 & $\mathrm{NASH}$ & $\mathrm{NASH}$ & S3A1F2 & significant \\
\hline 111 & $\mathrm{NASH}$ & $\mathrm{NASH}$ & $\mathrm{S} 2 \mathrm{~A} 4 \mathrm{~F} 1$ & significant \\
\hline 112 & steatosis & steatosis & S1A0F0 & mild \\
\hline 113 & $\mathrm{NASH}$ & $\mathrm{NASH}$ & S2A4F1 & significant \\
\hline 114 & steatosis & steatosis & S1A0F0 & mild \\
\hline 115 & $\mathrm{NASH}$ & $\mathrm{NASH}$ & S3A1F2 & significant \\
\hline 116 & $\mathrm{NASH}$ & $\mathrm{NASH}$ & S3A1F2 & significant \\
\hline 117 & steatosis & steatosis & $\mathrm{S} 2 \mathrm{~A} 1 \mathrm{~F} 1$ & mild \\
\hline 118 & steatosis & steatosis & S2A1F1 & mild \\
\hline 119 & $\mathrm{NASH}$ & $\mathrm{NASH}$ & S2A4F1 & significant \\
\hline 120 & $\mathrm{NASH}$ & $\mathrm{NASH}$ & S3A3F2 & significant \\
\hline 121 & $\mathrm{NASH}$ & $\mathrm{NASH}$ & S3A1F2 & significant \\
\hline 122 & $\mathrm{NASH}$ & $\mathrm{NASH}$ & S2A4F1 & significant \\
\hline 123 & $\mathrm{NASH}$ & $\mathrm{NASH}$ & S3A1F2 & significant \\
\hline
\end{tabular}


Table V. Cont.

\begin{tabular}{|c|c|c|c|c|}
\hline Case & Reference classification & Algorithmic classification & SAF & Disease severity \\
\hline 124 & steatosis & steatosis & S1A1F1 & mild \\
\hline 125 & steatosis & steatosis & S1A1F1 & mild \\
\hline 126 & $\mathrm{NASH}$ & $\mathrm{NASH}$ & S3A4F3 & significant \\
\hline 127 & $\mathrm{NASH}$ & $\mathrm{NASH}$ & S3A3F2 & significant \\
\hline 128 & $\mathrm{NASH}$ & $\mathrm{NASH}$ & S2A4F1 & significant \\
\hline 129 & $\mathrm{NASH}$ & $\mathrm{NASH}$ & S3A1F2 & significant \\
\hline 130 & $\mathrm{NASH}$ & $\mathrm{NASH}$ & $\mathrm{S} 2 \mathrm{~A} 4 \mathrm{~F} 1$ & significant \\
\hline 131 & steatosis & steatosis & S1A0F0 & mild \\
\hline 132 & $\mathrm{NASH}$ & $\mathrm{NASH}$ & $\mathrm{S} 2 \mathrm{~A} 4 \mathrm{~F} 1$ & significant \\
\hline 133 & steatosis & steatosis & S1A0F0 & mild \\
\hline 134 & steatosis & steatosis & S1A0F0 & mild \\
\hline 135 & steatosis & steatosis & S1A0F0 & mild \\
\hline 136 & $\mathrm{NASH}$ & $\mathrm{NASH}$ & S3A1F2 & significant \\
\hline 137 & $\mathrm{NASH}$ & $\mathrm{NASH}$ & $\mathrm{S} 2 \mathrm{~A} 4 \mathrm{~F} 1$ & significant \\
\hline 138 & steatosis & steatosis & S1A0F0 & mild \\
\hline 139 & steatosis & steatosis & S1A0F0 & mild \\
\hline 140 & steatosis & steatosis & S1A0F0 & mild \\
\hline 141 & $\mathrm{NASH}$ & $\mathrm{NASH}$ & S3A1F2 & significant \\
\hline 142 & $\mathrm{NASH}$ & $\mathrm{NASH}$ & $\mathrm{S} 2 \mathrm{~A} 4 \mathrm{~F} 1$ & significant \\
\hline 143 & steatosis & steatosis & S1A0F0 & mild \\
\hline 144 & steatosis & steatosis & S1A0F0 & mild \\
\hline 145 & steatosis & steatosis & S1A1F1 & mild \\
\hline 146 & steatosis & steatosis & S1A0F0 & mild \\
\hline 147 & $\mathrm{NASH}$ & $\mathrm{NASH}$ & S3A3F2 & significant \\
\hline 148 & $\mathrm{NASH}$ & $\mathrm{NASH}$ & S2A4F1 & significant \\
\hline 149 & $\mathrm{NASH}$ & $\mathrm{NASH}$ & S3A1F2 & significant \\
\hline 150 & $\mathrm{NASH}$ & $\mathrm{NASH}$ & S2A4F1 & significant \\
\hline 151 & steatosis & steatosis & S1A0F0 & mild \\
\hline 152 & $\mathrm{NASH}$ & $\mathrm{NASH}$ & S2A4F1 & significant \\
\hline 153 & steatosis & steatosis & S1A0F0 & mild \\
\hline 154 & steatosis & steatosis & S1A0F0 & mild \\
\hline 155 & steatosis & steatosis & S1A1F1 & mild \\
\hline 156 & steatosis & steatosis & S1A0F0 & mild \\
\hline 157 & $\mathrm{NASH}$ & $\mathrm{NASH}$ & S3A3F2 & significant \\
\hline 158 & $\mathrm{NASH}$ & $\mathrm{NASH}$ & $\mathrm{S} 2 \mathrm{~A} 4 \mathrm{~F} 1$ & significant \\
\hline 159 & $\mathrm{NASH}$ & $\mathrm{NASH}$ & S3A1F2 & significant \\
\hline 160 & $\mathrm{NASH}$ & $\mathrm{NASH}$ & $\mathrm{S} 2 \mathrm{~A} 4 \mathrm{~F} 1$ & significant \\
\hline 161 & steatosis & steatosis & S1A0F0 & mild \\
\hline 162 & $\mathrm{NASH}$ & $\mathrm{NASH}$ & $\mathrm{S} 2 \mathrm{~A} 4 \mathrm{~F} 1$ & significant \\
\hline 163 & steatosis & steatosis & S1A0F0 & mild \\
\hline 164 & steatosis & steatosis & S1A0F0 & mild \\
\hline 165 & steatosis & steatosis & $\mathrm{S} 1 \mathrm{~A} 1 \mathrm{~F} 1$ & mild \\
\hline 166 & steatosis & steatosis & S1A0F0 & mild \\
\hline 167 & steatosis & steatosis & S1A0F0 & mild \\
\hline 168 & steatosis & steatosis & S1A1F1 & mild \\
\hline 169 & steatosis & steatosis & S1A0F0 & mild \\
\hline
\end{tabular}


Table V. Cont.

\begin{tabular}{|c|c|c|c|c|}
\hline Case & Reference classification & Algorithmic classification & SAF & Disease severity \\
\hline 170 & $\mathrm{NASH}$ & NASH & S3A3F2 & significant \\
\hline 171 & NASH & NASH & $\mathrm{S} 2 \mathrm{~A} 4 \mathrm{~F} 1$ & significant \\
\hline 172 & NASH & NASH & S3A1F2 & significant \\
\hline 173 & NASH & NASH & S2A4F1 & significant \\
\hline 174 & steatosis & steatosis & S1A0F0 & mild \\
\hline 175 & $\mathrm{NASH}$ & $\mathrm{NASH}$ & S2A4F1 & significant \\
\hline 176 & steatosis & steatosis & S1A0F0 & mild \\
\hline 177 & $\mathrm{NASH}$ & $\mathrm{NASH}$ & S3A1F2 & significant \\
\hline 178 & steatosis & steatosis & S2A1F1 & mild \\
\hline 179 & steatosis & steatosis & $\mathrm{S} 2 \mathrm{~A} 1 \mathrm{~F} 1$ & mild \\
\hline 180 & $\mathrm{NASH}$ & $\mathrm{NASH}$ & $\mathrm{S} 2 \mathrm{~A} 4 \mathrm{~F} 1$ & significant \\
\hline 181 & $\mathrm{NASH}$ & $\mathrm{NASH}$ & S3A3F2 & significant \\
\hline 182 & $\mathrm{NASH}$ & $\mathrm{NASH}$ & S3A1F2 & significant \\
\hline 183 & $\mathrm{NASH}$ & $\mathrm{NASH}$ & $\mathrm{S} 2 \mathrm{~A} 4 \mathrm{~F} 1$ & significant \\
\hline 184 & $\mathrm{NASH}$ & $\mathrm{NASH}$ & S3A1F2 & significant \\
\hline 185 & steatosis & steatosis & $\mathrm{S} 1 \mathrm{~A} 1 \mathrm{~F} 1$ & mild \\
\hline 186 & steatosis & steatosis & $\mathrm{S} 1 \mathrm{~A} 1 \mathrm{~F} 1$ & mild \\
\hline 187 & $\mathrm{NASH}$ & $\mathrm{NASH}$ & S3A4F3 & significant \\
\hline 188 & $\mathrm{NASH}$ & $\mathrm{NASH}$ & S3A3F2 & significant \\
\hline 189 & $\mathrm{NASH}$ & $\mathrm{NASH}$ & $\mathrm{S} 2 \mathrm{~A} 4 \mathrm{~F} 1$ & significant \\
\hline 190 & $\mathrm{NASH}$ & $\mathrm{NASH}$ & S3A1F2 & significant \\
\hline 191 & $\mathrm{NASH}$ & $\mathrm{NASH}$ & S2A4F1 & significant \\
\hline 192 & steatosis & steatosis & S1A0F0 & mild \\
\hline 193 & $\mathrm{NASH}$ & $\mathrm{NASH}$ & S2A4F1 & significant \\
\hline 194 & steatosis & steatosis & S1A0F0 & mild \\
\hline 195 & $\mathrm{NASH}$ & $\mathrm{NASH}$ & S3A1F2 & significant \\
\hline 196 & $\mathrm{NASH}$ & $\mathrm{NASH}$ & S3A1F2 & significant \\
\hline 197 & steatosis & steatosis & S2A1F1 & mild \\
\hline 198 & steatosis & steatosis & S2A1F1 & mild \\
\hline 199 & $\mathrm{NASH}$ & $\mathrm{NASH}$ & $\mathrm{S} 2 \mathrm{~A} 4 \mathrm{~F} 1$ & significant \\
\hline 200 & $\mathrm{NASH}$ & $\mathrm{NASH}$ & S3A3F2 & significant \\
\hline
\end{tabular}

Reference interpretation: is the initial evaluation done by pathologist using accepted criteria, algorithm and SAF score. Algorithmic classification: (steatosis vs. NASH) after using the algorithm. Based on SAF score: mild for $A<2$ and F< 2 or significant for $A>2$ and/or $F>2$.

carcinogenesis CD24 is highly expressed in the liver progenitor cells [34].

Furthermore, $C D 24$ polymorphism may affect the immune/inflammatory response through T-cell activation. T-cell-mediated inflammation is one of the important mechanisms for the prevalence of HCC in HBV infected mice; it also affects the production of cytokines from liver necrotic cells [35] CD24 P170 $\mathrm{T} / \mathrm{T}$ is a higher cell-surface genotype than $\mathrm{P} 170 \mathrm{C} / \mathrm{T}$ or $\mathrm{P} 170 \mathrm{C} / \mathrm{C}$ genotypes, which increases the rapid progression and risk of multiple sclerosis (MS). Dinucleotide deletion in 3 untranslated regions (UTRs) is associated with protection from systemic lupus erythematosus and MS, as that deletion reduces the stability of CD24 messenger RNA [36].
Talin-1 has an important role in the stimulation of integrin. Especially, the sensitivity of talin-1 for cancer diagnosis was stronger than that of AFP in Egyptian patients with HCC [37]. Obviously, these results indicate that talin-1 is a possible diagnostic indicator for HCC. This was also investigated by another recent study which was performed on 90 Egyptian subjects showing that talin-1 is involved in the carcinogenesis of HCC [14]. Even so, whether talin-1 stimulated HCC proliferation and metastases was still unknown, and the role of talin-1 in HCC proliferation remained under investigation [38].

Talin-1 has been shown to facilitate HCC progression by inhibiting the activity of apoptosis con- 
Table VI. Evaluation of liver biopsies by the liver pathologists in hepatitis C virus patients without hepatocellular carcinoma

\begin{tabular}{|c|c|c|c|c|}
\hline Case & Reference classification & Algorithmic classification & SAF & Disease severity \\
\hline 1 & steatosis & steatosis & S1A1F1 & mild \\
\hline 2 & steatosis & steatosis & S1A1F1 & mild \\
\hline 3 & NASH & NASH & S1A4F3 & significant \\
\hline 4 & $\mathrm{NASH}$ & $\mathrm{NASH}$ & S3A1F2 & significant \\
\hline 5 & NASH & $\mathrm{NASH}$ & S2A4F1 & significant \\
\hline 6 & steatosis & steatosis & S1A1F1 & mild \\
\hline 7 & steatosis & steatosis & S1A1F1 & mild \\
\hline 8 & steatosis & steatosis & S1A1F1 & mild \\
\hline 9 & NASH & $\mathrm{NASH}$ & S3A1F2 & significant \\
\hline 10 & NASH & $\mathrm{NASH}$ & S2A4F1 & significant \\
\hline 11 & steatosis & steatosis & S1AOF0 & mild \\
\hline 12 & steatosis & steatosis & S1A1F1 & mild \\
\hline 13 & steatosis & steatosis & S1A1F1 & mild \\
\hline 14 & steatosis & steatosis & S1A1F1 & mild \\
\hline 15 & NASH & NASH & S3A1F2 & significant \\
\hline 16 & steatosis & steatosis & S1A1F1 & mild \\
\hline 17 & steatosis & steatosis & S1A1F1 & mild \\
\hline 18 & $\mathrm{NASH}$ & $\mathrm{NASH}$ & S3A4F3 & significant \\
\hline 19 & NASH & NASH & S3A3F2 & significant \\
\hline 20 & $\mathrm{NASH}$ & $\mathrm{NASH}$ & S2A4F1 & significant \\
\hline 21 & $\mathrm{NASH}$ & NASH & S2A4F1 & significant \\
\hline 22 & steatosis & steatosis & S1A1F1 & mild \\
\hline 23 & steatosis & steatosis & S1AOFO & mild \\
\hline 24 & steatosis & steatosis & S1A1F1 & mild \\
\hline 25 & NASH & NASH & S3A3F2 & significant \\
\hline 26 & steatosis & steatosis & S2A1F1 & mild \\
\hline 27 & steatosis & steatosis & S1A1F1 & mild \\
\hline 28 & NASH & NASH & S2A4F1 & significant \\
\hline 29 & steatosis & steatosis & S1AOFO & mild \\
\hline 30 & steatosis & steatosis & S1A1F1 & mild \\
\hline 31 & steatosis & steatosis & S1AOFO & mild \\
\hline 32 & NASH & NASH & S3A3F2 & significant \\
\hline 33 & NASH & NASH & S3A1F2 & significant \\
\hline 34 & NASH & $\mathrm{NASH}$ & S3A1F2 & significant \\
\hline 35 & NASH & NASH & S2A4F1 & significant \\
\hline 36 & NASH & NASH & S3A1F2 & significant \\
\hline 37 & steatosis & steatosis & S1A1F1 & mild \\
\hline 38 & steatosis & steatosis & S1AOFO & mild \\
\hline 39 & steatosis & steatosis & S1AOFO & mild \\
\hline 40 & $\mathrm{NASH}$ & NASH & S3A3F2 & significant \\
\hline 41 & steatosis & steatosis & S3A1F0 & mild \\
\hline 42 & steatosis & steatosis & S3A1F0 & mild \\
\hline 43 & steatosis & steatosis & S1AOFO & mild \\
\hline 44 & NASH & NASH & S3A1F2 & significant \\
\hline 45 & steatosis & steatosis & S3A1F0 & mild \\
\hline
\end{tabular}


Table VI. Cont.

\begin{tabular}{|c|c|c|c|c|}
\hline Case & Reference classification & Algorithmic classification & SAF & Disease severity \\
\hline 46 & steatosis & steatosis & S1A1F1 & mild \\
\hline 47 & $\mathrm{NASH}$ & $\mathrm{NASH}$ & S3A3F2 & significant \\
\hline 48 & $\mathrm{NASH}$ & $\mathrm{NASH}$ & S3A3F2 & significant \\
\hline 49 & $\mathrm{NASH}$ & $\mathrm{NASH}$ & S2A4F1 & significant \\
\hline 50 & steatosis & steatosis & S3A1F0 & mild \\
\hline 51 & steatosis & steatosis & S1A1F1 & mild \\
\hline 52 & steatosis & steatosis & S3A1F0 & mild \\
\hline 53 & $\mathrm{NASH}$ & NASH & S2A4F1 & significant \\
\hline 54 & steatosis & steatosis & $\mathrm{S} 1 \mathrm{~A} 1 \mathrm{~F} 1$ & mild \\
\hline 55 & $\mathrm{NASH}$ & $\mathrm{NASH}$ & S3A1F2 & significant \\
\hline 56 & $\mathrm{NASH}$ & $\mathrm{NASH}$ & S2A4F1 & significant \\
\hline 57 & steatosis & steatosis & S2A1F1 & mild \\
\hline 58 & steatosis & steatosis & S1A1F1 & mild \\
\hline 59 & $\mathrm{NASH}$ & $\mathrm{NASH}$ & S3A1F2 & significant \\
\hline 60 & steatosis & steatosis & S2A1F1 & mild \\
\hline 61 & steatosis & steatosis & $\mathrm{S} 2 \mathrm{~A} 1 \mathrm{~F} 1$ & mild \\
\hline 62 & $\mathrm{NASH}$ & $\mathrm{NASH}$ & S2A4F1 & significant \\
\hline 63 & $\mathrm{NASH}$ & $\mathrm{NASH}$ & S3A3F2 & significant \\
\hline 64 & $\mathrm{NASH}$ & $\mathrm{NASH}$ & S3A1F2 & significant \\
\hline 65 & $\mathrm{NASH}$ & $\mathrm{NASH}$ & $\mathrm{S} 2 \mathrm{~A} 4 \mathrm{~F} 1$ & significant \\
\hline 66 & steatosis & steatosis & $\mathrm{S} 1 \mathrm{~A} 1 \mathrm{~F} 1$ & mild \\
\hline 67 & steatosis & steatosis & S2A1F1 & mild \\
\hline 68 & steatosis & steatosis & S1A1F1 & mild \\
\hline 69 & $\mathrm{NASH}$ & NASH & S2A4F1 & significant \\
\hline 70 & steatosis & steatosis & S1A0F0 & mild \\
\hline 71 & $\mathrm{NASH}$ & $\mathrm{NASH}$ & S3A1F2 & significant \\
\hline 72 & $\mathrm{NASH}$ & $\mathrm{NASH}$ & S2A4F1 & significant \\
\hline 73 & steatosis & steatosis & S1A0F0 & mild \\
\hline 74 & steatosis & steatosis & $\mathrm{S} 1 \mathrm{~A} 1 \mathrm{~F} 1$ & mild \\
\hline 75 & steatosis & steatosis & S1A1F1 & mild \\
\hline 76 & steatosis & steatosis & S1A1F1 & mild \\
\hline 77 & $\mathrm{NASH}$ & $\mathrm{NASH}$ & S3A1F2 & significant \\
\hline 78 & steatosis & steatosis & $\mathrm{S} 1 \mathrm{~A} 1 \mathrm{~F} 1$ & mild \\
\hline 79 & steatosis & steatosis & $\mathrm{S} 1 \mathrm{~A} 1 \mathrm{~F} 1$ & mild \\
\hline 80 & NASH & NASH & S3A4F3 & significant \\
\hline 81 & NASH & NASH & S3A3F2 & significant \\
\hline 82 & NASH & NASH & S2A4F1 & significant \\
\hline 83 & $\mathrm{NASH}$ & $\mathrm{NASH}$ & S3A1F2 & significant \\
\hline 84 & $\mathrm{NASH}$ & $\mathrm{NASH}$ & $\mathrm{S} 2 \mathrm{~A} 4 \mathrm{~F} 1$ & significant \\
\hline 85 & steatosis & steatosis & S1A0F0 & mild \\
\hline 86 & $\mathrm{NASH}$ & $\mathrm{NASH}$ & S2A4F1 & significant \\
\hline 87 & steatosis & steatosis & S1A0F0 & mild \\
\hline 88 & $\mathrm{NASH}$ & $\mathrm{NASH}$ & S3A1F2 & significant \\
\hline 89 & $\mathrm{NASH}$ & $\mathrm{NASH}$ & S2A4F1 & significant \\
\hline 90 & steatosis & steatosis & S1A0F0 & mild \\
\hline 91 & steatosis & steatosis & S1A1F1 & mild \\
\hline
\end{tabular}


Table VI. Cont.

\begin{tabular}{|c|c|c|c|c|}
\hline Case & Reference classification & Algorithmic classification & SAF & Disease severity \\
\hline 92 & steatosis & steatosis & S1A1F1 & mild \\
\hline 93 & steatosis & steatosis & S1A1F1 & mild \\
\hline 94 & $\mathrm{NASH}$ & $\mathrm{NASH}$ & S3A1F2 & significant \\
\hline 95 & $\mathrm{NASH}$ & $\mathrm{NASH}$ & S2A4F1 & significant \\
\hline 96 & steatosis & steatosis & S1A0F0 & mild \\
\hline 97 & steatosis & steatosis & S1A0F0 & mild \\
\hline 98 & $\mathrm{NASH}$ & $\mathrm{NASH}$ & S3A1F2 & significant \\
\hline 99 & $\mathrm{NASH}$ & $\mathrm{NASH}$ & S2A4F1 & significant \\
\hline 100 & steatosis & steatosis & S1A0F0 & mild \\
\hline 101 & steatosis & steatosis & S1A1F1 & mild \\
\hline 102 & steatosis & steatosis & S1A1F1 & mild \\
\hline 103 & steatosis & steatosis & S1A1F1 & mild \\
\hline 104 & $\mathrm{NASH}$ & $\mathrm{NASH}$ & S3A1F2 & significant \\
\hline 105 & steatosis & steatosis & S1A1F1 & mild \\
\hline 106 & steatosis & steatosis & S1A1F1 & mild \\
\hline 107 & $\mathrm{NASH}$ & $\mathrm{NASH}$ & S3A4F3 & significant \\
\hline 108 & $\mathrm{NASH}$ & $\mathrm{NASH}$ & S3A3F2 & significant \\
\hline 109 & $\mathrm{NASH}$ & $\mathrm{NASH}$ & S2A4F1 & significant \\
\hline 110 & $\mathrm{NASH}$ & $\mathrm{NASH}$ & S3A1F2 & significant \\
\hline 111 & $\mathrm{NASH}$ & $\mathrm{NASH}$ & S2A4F1 & significant \\
\hline 112 & steatosis & steatosis & S1A0F0 & mild \\
\hline 113 & $\mathrm{NASH}$ & $\mathrm{NASH}$ & S2A4F1 & significant \\
\hline 114 & steatosis & steatosis & S1A0F0 & mild \\
\hline 115 & $\mathrm{NASH}$ & $\mathrm{NASH}$ & S3A1F2 & significant \\
\hline 116 & $\mathrm{NASH}$ & $\mathrm{NASH}$ & S2A4F1 & significant \\
\hline 117 & steatosis & steatosis & S1A0F0 & mild \\
\hline 118 & steatosis & steatosis & S1A1F1 & mild \\
\hline 119 & steatosis & steatosis & S1A1F1 & mild \\
\hline 120 & steatosis & steatosis & S1A1F1 & mild \\
\hline 121 & $\mathrm{NASH}$ & $\mathrm{NASH}$ & S3A1F2 & significant \\
\hline 122 & $\mathrm{NASH}$ & $\mathrm{NASH}$ & S2A4F1 & significant \\
\hline 123 & steatosis & steatosis & S1A0F0 & mild \\
\hline 124 & $\mathrm{NASH}$ & NASH & S3A3F2 & significant \\
\hline 125 & $\mathrm{NASH}$ & $\mathrm{NASH}$ & S2A4F1 & significant \\
\hline 126 & $\mathrm{NASH}$ & NASH & S3A1F2 & significant \\
\hline 127 & NASH & $\mathrm{NASH}$ & S2A4F1 & significant \\
\hline 128 & steatosis & steatosis & S1A0F0 & mild \\
\hline 129 & $\mathrm{NASH}$ & $\mathrm{NASH}$ & S2A4F1 & significant \\
\hline 130 & steatosis & steatosis & S1A0F0 & mild \\
\hline 131 & $\mathrm{NASH}$ & $\mathrm{NASH}$ & S3A1F2 & significant \\
\hline 132 & $\mathrm{NASH}$ & $\mathrm{NASH}$ & $\mathrm{S} 2 \mathrm{~A} 4 \mathrm{~F} 1$ & significant \\
\hline 133 & steatosis & steatosis & S1A0F0 & mild \\
\hline 134 & steatosis & steatosis & $\mathrm{S} 1 \mathrm{~A} 1 \mathrm{~F} 1$ & mild \\
\hline 135 & steatosis & steatosis & $\mathrm{S} 1 \mathrm{~A} 1 \mathrm{~F} 1$ & mild \\
\hline 136 & steatosis & steatosis & S1A1F1 & mild \\
\hline 137 & $\mathrm{NASH}$ & $\mathrm{NASH}$ & S3A1F2 & significant \\
\hline
\end{tabular}


Table VI. Cont.

\begin{tabular}{|c|c|c|c|c|}
\hline Case & Reference classification & Algorithmic classification & SAF & Disease severity \\
\hline 138 & $\mathrm{NASH}$ & $\mathrm{NASH}$ & $\mathrm{S} 2 \mathrm{~A} 4 \mathrm{~F} 1$ & significant \\
\hline 139 & steatosis & steatosis & S1A0F0 & mild \\
\hline 140 & steatosis & steatosis & S1A0F0 & mild \\
\hline 141 & $\mathrm{NASH}$ & $\mathrm{NASH}$ & S3A1F2 & significant \\
\hline 142 & $\mathrm{NASH}$ & $\mathrm{NASH}$ & S2A4F1 & significant \\
\hline 143 & steatosis & steatosis & S1A0F0 & mild \\
\hline 144 & steatosis & steatosis & S1A1F1 & mild \\
\hline 145 & $\mathrm{NASH}$ & $\mathrm{NASH}$ & S3A1F2 & significant \\
\hline 146 & $\mathrm{NASH}$ & $\mathrm{NASH}$ & $\mathrm{S} 2 \mathrm{~A} 4 \mathrm{~F} 1$ & significant \\
\hline 147 & steatosis & steatosis & S1A0F0 & mild \\
\hline 148 & $\mathrm{NASH}$ & $\mathrm{NASH}$ & S3A3F2 & significant \\
\hline 149 & NASH & $\mathrm{NASH}$ & S2A4F1 & significant \\
\hline 150 & NASH & $\mathrm{NASH}$ & S3A1F2 & significant \\
\hline 151 & $\mathrm{NASH}$ & $\mathrm{NASH}$ & $\mathrm{S} 2 \mathrm{~A} 4 \mathrm{~F} 1$ & significant \\
\hline 152 & steatosis & steatosis & S1A0F0 & mild \\
\hline 153 & $\mathrm{NASH}$ & $\mathrm{NASH}$ & $\mathrm{S} 2 \mathrm{~A} 4 \mathrm{~F} 1$ & significant \\
\hline 154 & steatosis & steatosis & S1A0F0 & mild \\
\hline 155 & $\mathrm{NASH}$ & $\mathrm{NASH}$ & S3A1F2 & significant \\
\hline 156 & $\mathrm{NASH}$ & $\mathrm{NASH}$ & $\mathrm{S} 2 \mathrm{~A} 4 \mathrm{~F} 1$ & significant \\
\hline 157 & steatosis & steatosis & S1A0F0 & mild \\
\hline 158 & steatosis & steatosis & $\mathrm{S} 1 \mathrm{~A} 1 \mathrm{~F} 1$ & mild \\
\hline 159 & steatosis & steatosis & S1A1F1 & mild \\
\hline 160 & steatosis & steatosis & S1A1F1 & mild \\
\hline 161 & $\mathrm{NASH}$ & $\mathrm{NASH}$ & S3A1F2 & significant \\
\hline 162 & $\mathrm{NASH}$ & $\mathrm{NASH}$ & S2A4F1 & significant \\
\hline 163 & steatosis & steatosis & S1A0F0 & mild \\
\hline 164 & steatosis & steatosis & S1A0F0 & mild \\
\hline 165 & $\mathrm{NASH}$ & $\mathrm{NASH}$ & S3A1F2 & significant \\
\hline 166 & $\mathrm{NASH}$ & $\mathrm{NASH}$ & $\mathrm{S} 2 \mathrm{~A} 4 \mathrm{~F} 1$ & significant \\
\hline 167 & steatosis & steatosis & S1A0F0 & mild \\
\hline 168 & steatosis & steatosis & S1A1F1 & mild \\
\hline 169 & steatosis & steatosis & S1A0F0 & mild \\
\hline 170 & $\mathrm{NASH}$ & $\mathrm{NASH}$ & S3A3F2 & significant \\
\hline 171 & $\mathrm{NASH}$ & $\mathrm{NASH}$ & $\mathrm{S} 2 \mathrm{~A} 4 \mathrm{~F} 1$ & significant \\
\hline 172 & $\mathrm{NASH}$ & $\mathrm{NASH}$ & S3A1F2 & significant \\
\hline 173 & $\mathrm{NASH}$ & $\mathrm{NASH}$ & $\mathrm{S} 2 \mathrm{~A} 4 \mathrm{~F} 1$ & significant \\
\hline 174 & steatosis & steatosis & S1A0F0 & mild \\
\hline 175 & $\mathrm{NASH}$ & $\mathrm{NASH}$ & $\mathrm{S} 2 \mathrm{~A} 4 \mathrm{~F} 1$ & significant \\
\hline 176 & steatosis & steatosis & S1A0F0 & mild \\
\hline 177 & $\mathrm{NASH}$ & $\mathrm{NASH}$ & S3A1F2 & significant \\
\hline 178 & NASH & $\mathrm{NASH}$ & S2A4F1 & significant \\
\hline 179 & steatosis & steatosis & S1A0F0 & mild \\
\hline 180 & steatosis & steatosis & $\mathrm{S} 1 \mathrm{~A} 1 \mathrm{~F} 1$ & mild \\
\hline 181 & steatosis & steatosis & S1A1F1 & mild \\
\hline 182 & steatosis & steatosis & S1A1F1 & mild \\
\hline 183 & $\mathrm{NASH}$ & $\mathrm{NASH}$ & S3A1F2 & significant \\
\hline
\end{tabular}


Table VI. Cont.

\begin{tabular}{|c|c|c|c|c|}
\hline Case & Reference classification & Algorithmic classification & SAF & Disease severity \\
\hline 184 & $\mathrm{NASH}$ & $\mathrm{NASH}$ & $\mathrm{S} 2 \mathrm{~A} 4 \mathrm{~F} 1$ & significant \\
\hline 185 & steatosis & steatosis & S1A0F0 & mild \\
\hline 186 & $\mathrm{NASH}$ & $\mathrm{NASH}$ & S3A3F2 & significant \\
\hline 187 & $\mathrm{NASH}$ & $\mathrm{NASH}$ & S2A4F1 & significant \\
\hline 188 & $\mathrm{NASH}$ & $\mathrm{NASH}$ & S3A1F2 & significant \\
\hline 189 & $\mathrm{NASH}$ & $\mathrm{NASH}$ & S2A4F1 & significant \\
\hline 190 & steatosis & steatosis & S1A0F0 & mild \\
\hline 191 & $\mathrm{NASH}$ & NASH & S2A4F1 & significant \\
\hline 192 & steatosis & steatosis & S1A0F0 & mild \\
\hline 193 & $\mathrm{NASH}$ & $\mathrm{NASH}$ & S3A1F2 & significant \\
\hline 194 & $\mathrm{NASH}$ & $\mathrm{NASH}$ & S2A4F1 & significant \\
\hline 195 & steatosis & steatosis & S1A0F0 & mild \\
\hline 196 & steatosis & steatosis & S1A1F1 & mild \\
\hline 197 & steatosis & steatosis & S1A1F1 & mild \\
\hline 198 & steatosis & steatosis & S1A1F1 & mild \\
\hline 199 & $\mathrm{NASH}$ & NASH & S3A1F2 & significant \\
\hline 200 & $\mathrm{NASH}$ & $\mathrm{NASH}$ & S2A4F1 & significant \\
\hline
\end{tabular}

Reference interpretation: is the initial evaluation done by the pathologist using accepted criteria, algorithm and SAF score. Algorithmic classification: (steatosis vs. NASH) after using the algorithm. Based on SAF score: mild for $A<2$ and $F<2$ or significant for $A>2$ and/or $F>2$.

Table VII. Odds ratio (OR) and 95\% confidence interval (CI) of clinical status and of CD24 C/T SNP 170 genotypic frequencies in 400 hepatitis $C$ virus patients

\begin{tabular}{|c|c|c|c|c|}
\hline \multirow[t]{2}{*}{ Variable } & \multicolumn{4}{|c|}{ Genotypic frequencies } \\
\hline & CC & $\mathrm{CT}+\mathrm{TT}$ & OR $(95 \% \mathrm{Cl})$ & $P$-value \\
\hline \multicolumn{5}{|c|}{ Clinical stage: } \\
\hline I/II & 160 (45.2\%) & 38 (53.4\%) & 1.00 & 0.537 \\
\hline III/IV & $30(32.7 \%)$ & $88(78.8 \%)$ & $1.121(0.371-1.640)$ & \\
\hline \multicolumn{5}{|c|}{ Lymph node metastasis: } \\
\hline No & $230(83.2 \%)$ & $64(74.4 \%)$ & 1.00 & $0.627^{*}$ \\
\hline Yes & $2(3.1 \%)$ & $10(4.6 \%)$ & $0.722(0.158-2.568)$ & \\
\hline \multicolumn{5}{|c|}{ Distant metastasis } \\
\hline No & $220(85.1 \%)$ & $65(83.4 \%)$ & 1.00 & 0.526 \\
\hline Yes & $9(4.9 \%)$ & $16(4.6 \%)$ & $1.453(0.542-2.786)$ & \\
\hline \multicolumn{5}{|c|}{ Vascular invasion: } \\
\hline No & $220(82.5 \%)$ & $60(55.9 \%)$ & 1.00 & $0.452^{*}$ \\
\hline Yes & $41(16.5 \%)$ & $200(83.1 \%)$ & $1.521(0.652-1.987)$ & \\
\hline \multicolumn{5}{|c|}{ Liver cirrhosis: } \\
\hline Negative & $52(19.8 \%)$ & $12(19.5 \%)$ & 1.00 & $0.821^{*}$ \\
\hline Positive & $80(20.1 \%)$ & $320(80.2 \%)$ & $1.562(0.634-1.823)$ & \\
\hline
\end{tabular}

The ORs with analyzed by their $95 \% \mathrm{Cls}$ were estimated by logistic regression models.

${ }^{\star} P$-value $<0.05$ indicates statistical significance.

siderations and the anti-apoptotic $\mathrm{BCL}_{2}$ members [39]. It also encourages HCC metastasis by inducing the release of mesenchymal epithelial-to-mesenchymal transition (EMT) markers and by reducing the activity of epithelial molecules. Talin-1 can stimulate HCC expansion and metastases through the regulation of electrical cell signaling and function as a promising bioelectricity target therapeutically [40]. In our research, the histological characteristics of HCC are prominent acinar patterns, mitotic activity, pseudoglandular or acinar and compact or solid patterns. Septae are observed 
and giant cells are also seen. The occurrence of liver biopsy steatosis in HCV patients is more expressed compared to other liver diseases such as autoimmune hepatitis and chronic hepatitis B. Steatosis is suggested to be 2.5 times more common in $\mathrm{HCV}$ patients relative to the normal community. Macrovesicular steatosis occurring in HCV patients is often distributed in the periportal and non-centrilobular regions, which are most frequently seen in NAFLD. All this implies that HCV can directly induce steatosis in these patients [41].

In summary, our study suggested that the CD24 polymorphism P170 CT/TT may affect both the prevalence of chronic HCV infection and HCC. Moreover, talin-1 gene expression was shown to facilitate HCC progression by reducing the activity of epithelial cells and through regulation of electrical cell signaling and inhibition of apoptosis.

In conclusions, CD24 polymorphism and the talin-1 gene expression outside the hematopoietic cells recently raised interest as a promising prognostic marker for progression of chronic HCV infection and HCC with better accuracy than serum AFP due to their high correlation with invasion and malignant growth of hepatocytes and the immune/inflammatory response in the liver tissue.

\section{Acknowledgements}

The authors thank Theodor Bilharz Research Institute (TBRI) for helping in samples' collection.

The study protocol was approved by the Ethics Committee of the Faculty of Pharmacy, Ahram Canadian University (ACU) Human Ethics Committee (PBC-2020-04).

\section{Conflict of interest}

The authors declare no conflict of interest.

\section{References}

1. Shawky EM, El-Beih N, El-Hussieny E, El-Ahwany E, Hassan $M$, Zoheiry $M$. Effects of free and nanoparticulate curcumin on chemically induced liver carcinoma in an animal model. Arch Med Sci 2021; 17: 218-27.

2. Abd-Elsalam S, Elwan N, Soliman $\mathrm{H}$, et al. Epidemiology of liver cancer in Nile delta over a decade: a single-center study. South Asian J Cancer 2018; 7: 24-6.

3. Sherman M. Hepatocellular carcinoma: epidemiology, surveillance, and diagnosis. Semin Liver Dis 2010; 30: 3-16.

4. Forner A, Lovet JM, Bruix J. Hepatocellular carcinoma. Lancet 2012; 379: 1245-55.

5. Gao J, Xie L, Yang WS, et al. Risk factors of hepatocellular carcinoma - current status and perspectives. Asian Pac J Cancer Prev 2012; 13: 743-52.

6. Sharma SD. Hepatitis C virus: molecular biology \& current therapeutic options. Indian J Med Res 2010; 131: 17-34.

7. Gottwein JM, Scheel TK, Jensen TB, et al. Development and characterization of hepatitis $C$ virus genotype 1-7 cell culture systems: role of CD81 and scavenger receptor class B type I and effect of antiviral drugs. Hepatology 2009; 49: 364-77.

8. Miki D, Ochi H, Hayes CN, Aikata H, Chayama K. Hepatocellular carcinoma: towards personalized medicine. Cancer Sci 2012; 103: 846-50.

9. Nahon P, Zucman-Rossi J. Single nucleotide polymorphisms and risk of hepatocellular carcinoma in cirrhosis. J Hepatol 2012; 57: 663-74.

10. Jin F, Xiong W, Jing JC, Feng Z, Qu LS, Shen X. Evaluation of the association studies of single nucleotide polymorphisms and hepatocellular carcinoma: a systematic review. J Cancer Res 2011; 137: 1095-104.

11. Simmonds P, Bukh J, Combet C, et al. Consensus proposals for a unified system of nomenclature of hepatitis $C$ virus genotypes. Hepatology 2005; 42: 962-73.

12. Siegel R, Desantis C, Jemal A. Colorectal cancer statistics. Cancer J Clin 2014; 64: 104-17.

13. Braliou GG, Pantavou KG, Kontou PI, Bagos PG. Polymorphisms of the CD24 gene are associated with wisk of multiple sclerosis: a meta-analysis. Int J Mol Sci 2015; 16: $12368-81$.

14. Austen K, Ringer P, Mehlich A, et al. Extracellular rigidity sensing by talin isoform-specific mechanical linkages. Nat Cell Biol 2015; 17: 1597-606.

15. Mashaly AH, Anwar R, Ebrahim MA, Eissa LA, Shishtawy MME. Diagnostic and prognostic value of talin-1 and midkine as tumor markers in hepatocellular carcinoma in Egyptian patients. Asian Pac J Cancer Prev 2018; 19: 1503-8

16. Vauthey JN, Lauwers G, Esnaola N, et al. Simplified staging for hepatocellular carcinoma. J Clin Oncol 2002; 20: 1527-36.

17. Kim HJ, Kim SY, Shin SP, et al. Immunological measurement of aspartate/alanine aminotransferase in predicting liver fibrosis and inflammation. Korean J Intern Med 2020; 35: 320-30

18. Karmen A. A note on the spectrometric assay of glutamic-oxalacetic transaminase in human blood serum. J Clin Invest 1955; 34: 131-3.

19. Yoon S, Lim N, Ha S, et al. The human cervical cancer oncogene protein is a biomarker for human hepatocellular carcinoma. Cancer Res 2004; 64: 5434- 41.

20. Hall P, Cash J. What is the Real Function of the Liver Function Tests? Ulster Med J 2012; 81: 30-6.

21. Huang G, Yang L, Lu W. Expression of hypoxia-inducible factor and vascular endothelial growth factor in hepatocellular carcinoma: Impact on neovascularization and survival. World J Gastroenterol 2005; 11: 1705-8.

22. Kawada N. Evolution of hepatic fibrosis research. Hepatol Res 2011; 41: 199-208.

23. Livak KJ, Schmittgen TD. Analysis of relative gene expression data using real-time quantitative $P C R$ and the 2(-Delta Delta C(T)) method. Methods 2001; 25: 402-8.

24. Sun J, Fang K, Shen H, Qian Y. MicroRNA-9 is a ponderable index for the prognosis of human hepatocellular carcinoma. Int J Clin Exp Med 2015; 8: 17748-56.

25. Alwahaibi NY, Alkhatri AS, Kumar JS. Hematoxylin and eosin stain shows a high sensitivity but sub-optimal specificity in demonstrating iron pigment in liver biopsies. Int J Appl Basic Med Res 2015; 5: 169-71.

26. Forlano R, Mullish BH, Giannakeas N, et al. High-throughput, machine learning-based quantification of steatosis, inflammation, ballooning, and fibrosis in biopsies from patients with nonalcoholic fatty liver disease. Clin Gastroenterol Hepatol 2020; 18: 2081-90. 
27. Munteanu M, Tiniakos D, Anstee $\mathrm{Q}$, et al. Diagnostic performance of Fibro-Test, Steato-Test and Acti-Test in patients with NAFLD using the SAF score as histological reference. Aliment Pharmacol Ther 2016; 44: 877-89.

28. Liu J, Chen L, Pan J, et al. Comprehensive analysis of key IncRNAs in HCV-positive hepatocellular carcinoma. Arch Med Sci 2021; 17: 142-51

29. Ibrahim SM, Bastawy AA. The relevance of single-nucleotide polymorphism $+62 \mathrm{G}>\mathrm{A}$ to the expression of resistin gene affecting serum resistin levels in metabolic syndrome in the Egyptian population. Curr Pharm Biotechnol 2020; 21: 626-34.

30. Wang L, Lin S, Rammohan KW, et al. A dinucleotide deletion in CD24 confers protection against autoimmune diseases. PLoS Genet 2007; 3: e49.

31. Li D, Zheng L, Jin L, et al. CD24 polymorphisms affect risk and progression of chronic hepatitis B virus infection. Hepatology 2009; 19: 735-42.

32. Robert F, Pelletier J. Exploring the impact of single-nucleotide polymorphisms on translation. Front Genet 2018; 9: 507.

33. Kristiansen G, Machado E, Bretz N, et al. Molecular and clinical dissection of CD24 antibody specificity by a comprehensive comparative analysis. Lab Invest 2010; 90: 1102-16.

34. Ochsner SA, Strick-Marchand H, Qiu Q, et al. Transcriptional profiling of bipotential embryonic liver cells to identify liver progenitor cell surface markers. Stem Cells 2007; 25: 2476-87.

35. Mihm S. Hepatitis C virus, diabetes and steatosis: clinical evidence in favor of a linkage and role of genotypes. Dig Dis 2010; 28: 280-4.

36. Mirza S, Siddiqui AR, Hamid S, Umar M, Bashir S. Extent of liver inflammation in predicting response to interferon $\alpha$ \& Ribavirin in chronic hepatitis $C$ patients: a cohort study. BMC Gastroenterol 2012; 12: 71.

37. Youns MM, Abdel Wahab AH, Hassan ZA, Attia MS. Serum talin-1 is a potential novel biomarker for diagnosis of hepatocellular carcinoma in Egyptian patients. Asian Pac J Cancer Prev 2013; 14: 3819-23.

38. Bostanci O, Kemik O, Kemik A, et al. A novel screening test for colon cancer: Talin-1. Eur Rev Med Pharmacol Sci 2014; 18: 2533-7.

39. Sakamoto S, McCann RO, Dhir R, Kyprianou N. Talin1 promotes tumor invasion and metastasis via focal adhesion signaling and anoikis resistance. Cancer Res 2010; 70: 1885-95.

40. Chen P, Zheng X, Zhou Y, Xu Y, Zhu L, Qian Y. Talin-1 interaction network promotes hepatocellular carcinoma progression. Oncotarget 2017; 8: 13003-14.

41. Zampino R, Marrone A, Rinaldi L, et al. Endotoxinemia contributes to steatosis, insulin resistance and atherosclerosis in chronic hepatitis C: the role of pro-inflammatory cytokines and oxidative stress. Infection 2018; 46: 793-9. 